\title{
Avaliação da acurácia de uma barra de luz utilizada na agricultura de precisão, em relação ao marcador de espuma
}

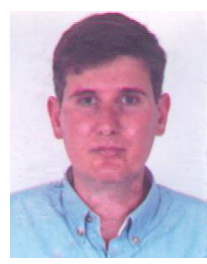

Fábio H. R. Baio1 ${ }^{1}$ Luiz A. Balastreire², Fábio Torres ${ }^{3}$ \& Affonso C. Ribeiro Filho ${ }^{3}$

1 ESALQ/USP. Piracicaba, SP. Fone: (019) 3429-4149. E-mail: fhrbaio@esalq.usp.br (Foto)
2 ESALQ/USP. Fone: (019) 3429-4165. E-mail: labalast@esalq.usp.br
${ }^{3}$ Máquinas Agrícolas Jacto S.A., Pompéia, SP. Fone: (014) 452-1811. E-mail: jacto@jacto.com.br

Protocolo $105-30 / 08 / 2000$

\begin{abstract}
Resumo: Alguns equipamentos utilizados na agricultura de precisão têm, por finalidade, a melhoria das condições operacionais. A barra de luz é um equipamento utilizado para a orientação de um veículo em faixas adjacentes, diminuindo a sobreposição da operação agrícola entre passadas consecutivas e otimizando a eficiência da aplicação agrícola. O presente trabalho teve por objetivo a determinação da acurácia da barra de luz em relação ao marcador de espuma e a verificação da adaptação dos operadores à nova tecnologia. Para tanto, foram realizados dois ensaios em locais distintos, com operadores diferentes e foram comparados os erros de sobreposição e falhas nas passadas adjacentes de um pulverizador automotriz. Ocorreu alta adaptação dos operadores à nova tecnologia, devido a uma facilidade operacional maior em relação ao marcador de espuma. Concluiu-se que o marcador de espuma pode ser substituído pela barra de luz na aplicação de defensivos agrícolas.
\end{abstract}

Palavras-chave: barra de luz, marcador de espuma, agricultura de precisão

\section{Evaluation of the accuracy of a light bar used in precision farming compared to a foam marker}

\begin{abstract}
Some equipments are used in precision farming to improve operational conditions. A light bar is an equipment used to guide a vehicle in adjacent bands, reducing the overlap of the parallel swathing and optimizing the efficiency of the agricultural application. The objective of this work was to determine the accuracy of a light bar compared to a foam marker, and to verify the adaptation of the operators to this new technology. Experiments were conducted at two different places with several operators. The overlap errors and missed applications in the parallel swathing system were compared for both systems. There was a high adaptability of the operators to the light bar since this system was easier to operate than the foam marker. It was concluded that the light bar for the application of agricultural chemicals could replace the foam marker.
\end{abstract}

Key words: light bar, foam marker guidance, precision farming

\section{INTRODUÇÃO}

A agricultura de precisão é uma nova tecnologia que está causando revolução na agricultura convencional. Muitos autores a citam como a terceira revolução tecnológica na agricultura (Balastreire, 1998) tendo em vista que ela propõe a utilização de equipamentos e máquinas agrícolas munidos de eletrônica embarcada, objetivando o melhor gerenciamento da área.

Muitos equipamentos utilizados na agricultura de precisão têm por finalidade a melhoria das condições operacionais. De acordo com Morgan (1997) o uso do DGPS (Differential Global Positioning System) na agricultura de precisão não está limitado apenas em determinar o posicionamento de um veículo no campo, mas pode ser utilizado também, para auxiliar na orientação de um veículo em uma operação agrícola, empregando um acessório chamado barra de luz.

A barra de luz é um equipamento utilizado para a orientação de um veículo em faixas adjacentes, com o propósito de diminuir a sobreposição entre passadas consecutivas e otimizar a eficiência da operação agrícola; ela possui um conjunto de LEDs verdes que se mantêm ligados quando o veículo está mantendo o alinhamento programado ou liga um conjunto de LEDs vermelhos quando o veículo está se afastando do alinhamento programado.

O uso de alguma sobreposição entre passadas adjacentes sucessivas é uma prática comum em muitas operações agrícolas, principalmente na pulverização; esta prática garante uma cobertura melhor do produto aplicado sobre o alvo, porém 
proporciona maior dispêndio de defensivo, aumento do custo da aplicação e maior contaminação do meio ambiente.

Segundo Morgan (1997) a aplicação precisa em linhas paralelas com marcadores de linhas convencionais é dificultada quando a faixa de aplicação excede $18 \mathrm{~m}$ ou quando a velocidade de aplicação é maior que $24 \mathrm{~km} \mathrm{~h}^{-1}$.

Para Molin (1998) a atividade precursora da utilização da barra de luz na agricultura foi a aviação agrícola. $\mathrm{O}$ autor comparou a acurácia da orientação de uma aeronave agrícola por DGPS em relação ao sistema convencional por bandeiras e verificou que o sistema de orientação por DPGS apresentou melhor desempenho na manutenção do alinhamento.

Molin \& Ruiz (1999) relatam a importância de um treinamento adequado dos operadores com a barra de luz para a obtenção de uma aplicação com melhores resultados. Eles citam, também, que a configuração inadequada da barra de luz pode diminuir a qualidade da aplicação, devido ao aumento do erro. Verificaram, ainda, que o aumento do erro está correlacionado com a diminuição da velocidade de aplicação.

Buick \& White (1998) realizaram uma comparação entre a operação guiada pela barra de luz e pelo marcador de espuma. $\mathrm{O}$ experimento foi realizado em duas áreas distintas, com dois operadores, em que um possuía experiência de dez anos com o marcador de espuma e nove meses com a barra de luz e o outro tinha experiência de um dia com os dois equipamentos. O ensaio foi realizado a uma velocidade de $12 \mathrm{~km} \mathrm{~h}^{-1}$. Foram calculados os erros de sobreposição e falhas na aplicação. Os autores verificaram que, para o operador com maior experiência, não houve diferença estatística entre os dois tratamentos, mas para o operador com menor experiência ocorreu melhor acurácia da operação com a barra de luz. Eles observaram, também, que a durabilidade da espuma é alterada de acordo com a condição climática e concluíram que o marcador de espuma pode ser substituído pela barra de luz nas operações agrícolas.

O presente trabalho teve por objetivo a determinação da acurácia da barra de luz em relação ao marcador de espuma e a verificação da adaptação dos operadores à nova tecnologia.

\section{MATERIAL E MÉTODOS}

O ensaio foi realizado em duas localidades, com áreas aproximadas de 45 ha, em Ituverava, SP, e em Araguari, MG; esses locais possuíam relevo plano e sem obstruções físicas para o recebimento dos sinais dos satélites GPS.

Para o posicionamento do veículo utilizou-se um receptor GPS modelo AG-132 da Trimble. A correção diferencial foi fornecida pela empresa Racal Land Star. A barra de luz utilizada foi a de modelo AgGPS Parallel Swathing Option da Trimble (Figura 1).

Como veículo, foi utilizado um pulverizador automotriz modelo Uniport 2000 da Jacto, com barras de $21 \mathrm{~m}$ de comprimento, dotado de um marcador de espuma Master Mark.

O pulverizador simulou a aplicação de um defensivo, passando em faixas adjacentes sucessivas sobre o terreno e deixando rastros do pneu sobre o solo, o que possibilitou a medição dos erros entre as passadas (Figuras 2A e B). A medição dos erros foi realizada perpendicularmente entre os centros dos rastros dos pneus de duas passadas adjacentes sucessivas do pulverizador (Figura 3). Os erros foram obtidos pela diferença

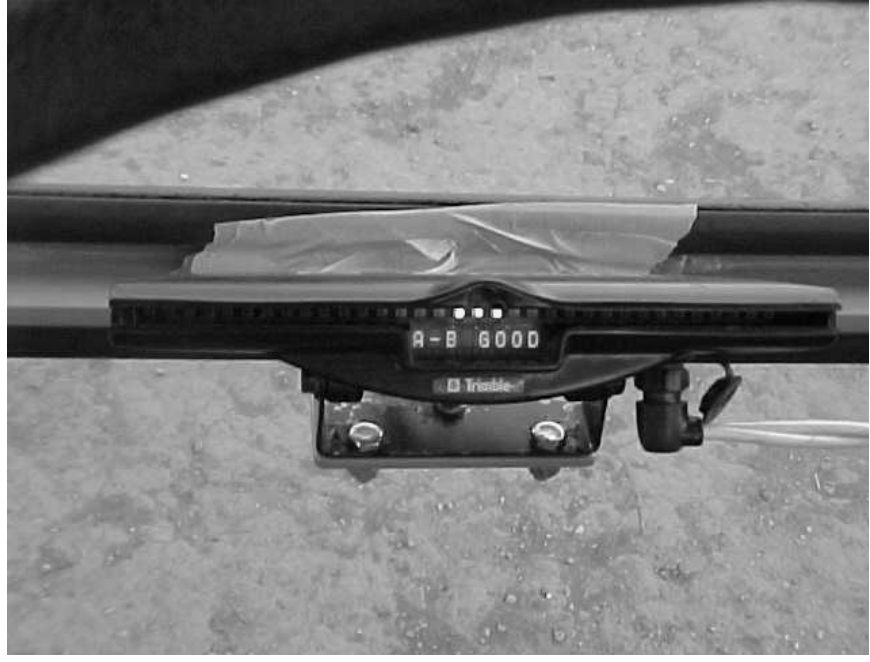

Fonte: Jacto

Figura 1. Barra de luz posicionada à frente do operador

entre a largura da faixa na ausência de erros (21 m) e a largura da faixa medida. As mensurações dos erros de sobreposição e falhas na aplicação foram realizadas aleatoriamente, com uma trena de $50 \mathrm{~m}$, sobre todo o percurso do pulverizador. Em cada passada o pulverizador percorria $800 \mathrm{~m}$.

\section{A. Ituverava}

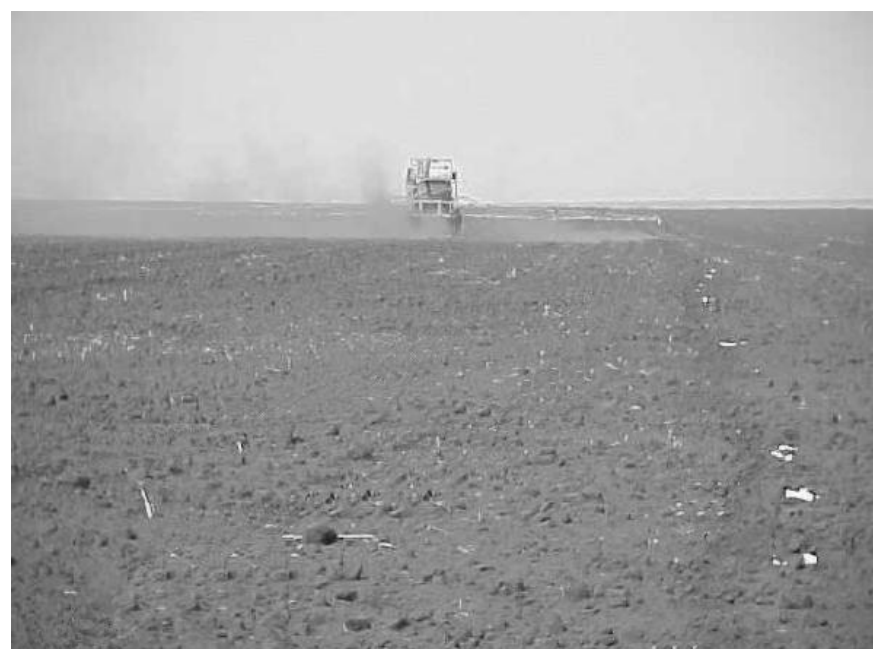

B. Araguari

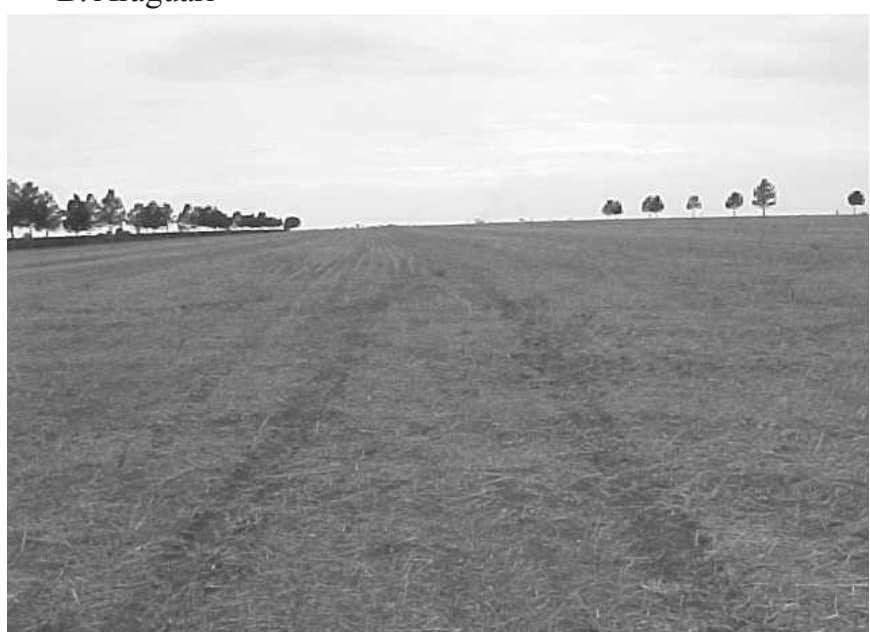

Figura 2. Área experimental de Ituverava (A) e área experimental de Araguari (B) 


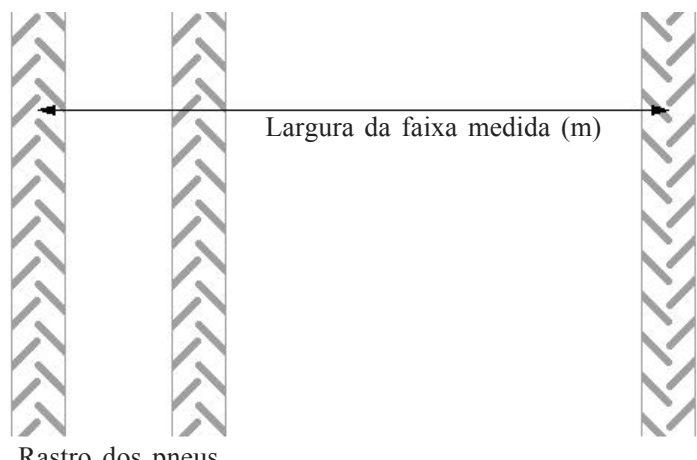

Figura 3. Mensuração da largura da faixa entre duas passadas adjacentes sucessivas do pulverizador

O delineamento estatístico utilizado foi o de blocos casualizados, com dois tratamentos e cinqüenta repetições cada um, em dois locais distintos. Para cada tratamento foram realizadas cinqüenta medições da largura da faixa de aplicação.

Os dois tratamentos utilizados foram: direcionamento do pulverizador pelo marcador de espuma em condições climáticas favoráveis e direcionamento do pulverizador pela barra de luz.

Todas as operações realizadas foram memorizadas em tempo real, por um notebook conectado ao GPS e em todos os tratamentos a velocidade de trabalho foi de $15 \mathrm{~km} \mathrm{~h}^{-1}$, indicada pelo radar do equipamento TASC 6600 da Mid-Tech.

Utilizou-se um anemômetro para avaliar a velocidade do vento nas operações com o marcador de espuma, cujo ensaio foi realizado em condições climáticas consideradas adequadas para a pulverização, com velocidade do vento abaixo de $3 \mathrm{~km} \mathrm{~h}^{-1} \mathrm{e}$ temperatura sempre inferior a $30^{\circ} \mathrm{C}$.

Em ambos os locais, os operadores do pulverizador automotriz já possuíam experiência com o marcador de espuma e necessitaram de um treinamento para a operação com a barra de luz, os quais o praticaram por uma hora antes da realização do ensaio.

A análise estatística dos resultados foi realizada com o auxílio do software SANEST. Foi realizado o teste de Duncan para a comparação das médias dos tratamentos.

\section{RESULTADOS E DISCUSSÃO}

Verificou-se que os operadores se adaptaram rapidamente à nova tecnologia, adquirindo prática com facilidade para operarem a barra de luz.

Verifica-se, na Figura 4A, que no tratamento "espuma" do ensaio realizado em Ituverava, 32\% dos dados observados possuíram erros acima de $1 \mathrm{~m}$ e $2 \%$ dos dados observados apresentaram erros maiores que 1,4 m; já no tratamento "barra de luz" $66 \%$ dos dados amostrados estiveram abaixo de $0,2 \mathrm{~m}$, não sendo observados erros acima de $0,8 \mathrm{~m}$.

No segundo ensaio, realizado em Araguari, constatou-se que os dados amostrados estiveram muito próximos aos observados no primeiro ensaio, como ilustra a Figura 4B. Não se observaram erros acima de $0,8 \mathrm{~m}$ no tratamento "barra de luz" e $50 \%$ dos dados amostrados estiveram abaixo de $0,2 \mathrm{~m}$, enquanto no tratamento "espuma" $12 \%$ dos dados amostrados estiveram acima de $1 \mathrm{~m}$.

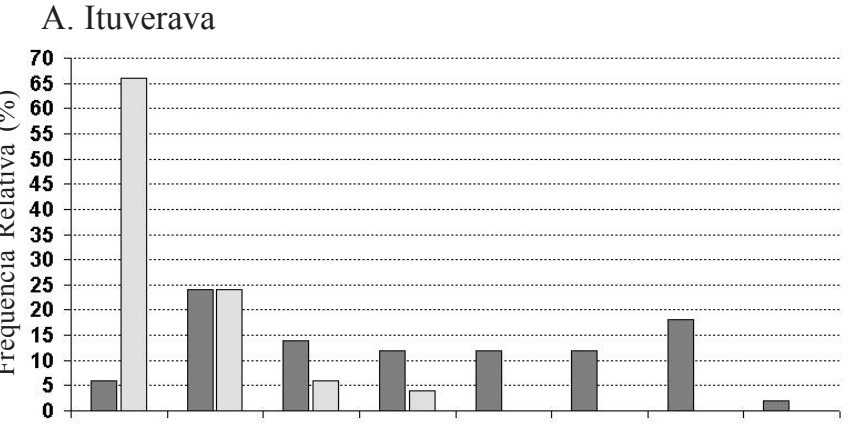

$$
\text { B. Araguari }
$$

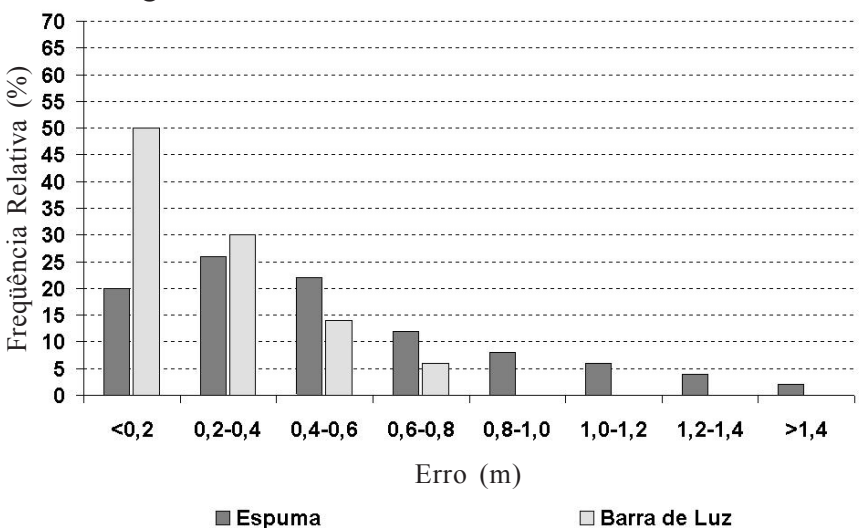

Figura 4. Comparação das freqüências relativas das observações realizadas nos tratamentos "espuma" e "barra de luz", em Ituverava (A) e em Araguari (B)

De acordo com a análise estatística realizada para a comparação das médias dos tratamentos, verificou-se necessidade da transformação dos dados pela raiz quadrada do valor somado a 0,5, e foi necessário para a obtenção de uma homogeneidade maior da variância.

Como se verifica na Tabela 1 , o erro médio obtido no tratamento "barra de luz" foi de $0,189 \mathrm{~m}$, enquanto no tratamento “espuma” ele foi de $0,574 \mathrm{~m}$.

Tabela 1. Análise estatística dos dados e teste de Duncan para as médias dos tratamentos

\begin{tabular}{lccccc}
\hline Tratamento & $\begin{array}{c}\text { Número de } \\
\text { Repetições }\end{array}$ & $\begin{array}{c}\text { Médias } \\
(\mathrm{m})^{1}\end{array}$ & $\begin{array}{c}\text { Médias } \\
\text { Originais }(\mathrm{m})\end{array}$ & $5 \%{ }^{2}$ & $1 \%{ }^{2}$ \\
\hline Espuma & 100 & 1,036 & 0,574 & $\mathrm{a}$ & $\mathrm{A}$ \\
Barra de luz & 100 & 0,830 & 0,189 & $\mathrm{~b}$ & $\mathrm{~B}$ \\
\hline
\end{tabular}

${ }^{1}$ Foi necessária a transformação dos dados por $\sqrt{\mathrm{x}+0,5}$ para maior homogeneidade da variância, em que $\mathrm{x}$ foi o valor observado

${ }^{2}$ Médias seguidas por letras distintas na coluna diferem estatisticamente pelo teste de Duncan, a nível de significância indicado

Pode-se observar, também, que o tratamento "barra de luz" obteve o melhor resultado estatístico,a nível de 1\% de significância.

\section{CONCLUSÕES}

1. A barra de luz possui grande acurácia para o direcionamento do pulverizador, quando comparada ao marcador de espuma.

2. Houve alta adaptabilidade dos operadores à nova tecnologia, devido a uma facilidade operacional maior, em relação ao marcador de espuma. 
3. O marcador de espuma pode ser substituído pela barra de luz na aplicação de defensivos agrícolas.

\section{AGRADECIMENTOS}

À empresa Máquinas Agrícolas Jacto S.A., pelo apoio técnico na realização deste experimento.

\section{LITERATURA CITADA}

Balastreire, L.A. Histórico, definições e conceitos básicos. In: Balastreire, L.A. (ed.). Agricultura de precisão. Piracicaba: Balastreire, L.A., 1998. p.1-8.
Buick, R.; White, E. Comparing GPS guidance with foam marker guidance. ln: International Conference on Precision Agriculture, 4, 1998, Madison. Resumos... Madison: ASACSSA-SSSA, 1998. p.1035-1045.

Molin, J.P. Orientação de aeronave agrícola por DGPS comparada com sistema convencional por bandeiras. Engenharia Agrícola, Jaboticabal, v.18, n.2, p.62-70, 1998.

Molin, J.P.; Ruiz, E.R.S. Accuracy of DGPS for ground application in parallel swaths. St. Joseph: ASAE, 1999. 7p. Paper, 991043

Morgan, M. The precision farming: Guide for agriculturists. 1.ed. Moline: Deere \& Company, 1997. 117p. 